\title{
Quality assessment and Analytical Quality by Design-based RP-HPLC method development for quantification of Piperine in Piper nigrum L.
}

\author{
Vishakha Parab Gaonkar ${ }^{1 *} \mathbb{D}$, Vinodh Kumar Mannur ${ }^{1 *}$ and Kirankumar Hullatti ${ }^{2}$
}

\begin{abstract}
Background: Piper nigrum L. is one of the widely used herbs in Ayurvedic medicine. Piperine is a major phytoconstituent that is responsible for most of the activity of the herb. Quality assessment and standardization of such phytoconstituents is the need of the hour. The present study aims at developing a Quality by design (QbD)-based RP-HPLC Method for marker-based standardization of Piper nigrum L. fruits along with its quality assessment.

Results: The quality assessment of the crude sample was carried out by evaluating pharmacognostic parameters and analysis of toxic contaminants. The analytical target profile and critical quality attributes were determined and $2^{2}$ factorial design was employed for optimization of the method. By performing the experiments as per the QbD concept the optimized mobile phase was identified as Acetonitrile and Water with 0.05\% Acetic acid in the ratio of 70:30, with a flow rate of $1 \mathrm{~mL} / \mathrm{min}$ and UV detection at $342 \mathrm{~nm}$. The retention time of Piperine was found to be $5.5 \mathrm{~min}$ and the amount of Piperine in crude P. nigrum fruits and its extract was found to be $3.6 \% \mathrm{w} / \mathrm{w} 5.62 \% \mathrm{w} / \mathrm{w}$, respectively. The Pharmacognostic parameters showed the results within specified limits and the crude drug sample showed the absence of toxic contaminants in it thus indicating the purity of the drug.
\end{abstract}

Conclusion: The utilization of the $\mathrm{QbD}$ approach leads to the development of a more precise and reliable method for the quantification of phytocompounds.

Keywords: Piper nigrum L., Piperine, Quality by design, Quality assessment, RP-HPLC

\section{Background}

Herbal drugs have been used in medical practice for many years and are gaining considerable momentum in the world during the past decades [1]. As the requirements of herbal drugs are increasing worldwide, their quality control and standardization have become more imperative. Since quality control and standardization of herbal drugs is an important task with great challenges; factors such as geographic and environmental differences of growing conditions, physical constants, adulterations,

\footnotetext{
*Correspondence: vishakhaparab70@gmail.com; drvsmannur@gmail.com ${ }^{1}$ Department of Pharmaceutical Quality Assurance, KLE College of Pharmacy, Belagavi, KLE Academy of Higher Education and Research, Belagavi, Karnataka, India

Full list of author information is available at the end of the article
}

microbiological contamination, and foreign materials could affect the quality and also batch-to-batch uniformity of herbal products. Hence quality assessment of raw material concerning pharmacognostic and phytochemical parameters is essential in order to prove the identity and purity of herbal drugs $[2,3]$.

Chemical marker-based standardization is a widely accepted method for the quality control of herbal drugs. In these methods, suitable markers or pharmacologically active compounds in the herb are analyzed by various chromatographic techniques for evaluating the quality and authenticity of herbal medicines. Several chromatographic techniques ranging from simplest Thin Layer Chromatography to sophisticated HighPerformance Liquid Chromatography (HPLC), HighPerformance Thin Layer Chromatography (HPTLC), 
and Gas Chromatography (GC) can be utilized for such marker-based standardization of herbal drugs [4].

Along with the utilization of marker-based techniques, the application of novel quality approaches are essential for quality assessment and development standardization parameters for herbal drugs. In recent times, pharmaceutical companies adopting Quality by Dsign (QbD) as a fundamental pharmaceutical quality model [5]. Quality by Design is defined as "a systematic approach to development that begins with predefined objectives and emphasizes product and process understanding based on sound science and quality risk management" [6]. According to the recent literature the QbD concept can serve as a novel approach for quality control of herbal drugs [7-9].

Application of the QbD approach in analytics is one of the alternatives which reduces the experimental time and cost for drug analysis. The $\mathrm{QbD}$ approach suggests looking into the quality of the analytical process during the development stage itself. Analytical QbD explores the scientific understanding of method variables and their interactions, finally provides a region for a highly robust and cost-effective approach $[3,10,11]$.

Piper nigrum L. belongs to the family Piperaceae and is known as the Black pepper or king of spices. Black pepper fruits are the source of one of the world's most widely and frequently used spices. The fruits of the plant have a long history of usage in Ayurvedic and folklore medicine, particularly for digestive ailments [12]. The main chemical constituents of fruits are alkaloids, among the alkaloid content Piperine is a major phytoconstituent that is responsible for most of the activity of the herb. In Ayurvedic medicine, black pepper has been used to aid digestion, improve appetite, treat coughs, colds, breathing and heart problems, colic, diabetes, anemia, and piles. It improves drug availability and is used as a bio enhancer due to its ability to enhance the efficacy of other drugs $[13,14]$. In the present research work, an attempt has been made to develop quality control standards for $P$. nigrum fruits by carrying out the pharmacognostic evaluation along with chemical marker-based standardization of $P$. nigrum fruits by application of the Analytical QbD approach.

\section{Methods \\ Chemicals}

Standard Piperine was provided as a gift sample by the Himalaya drug company, Bengaluru India. Acetonitrile and water of HPLC grade purchased from Merck, Mumbai, India Pvt Ltd. Other chemicals and reagents used in the research work were of analytical grade.

\section{Plant material and processing}

Sample of crude Piper nigrum L. fruits was procured and authenticated from Shri B. M. Kankanwadi Ayurveda Mahavidyalaya, Karnataka. The fruits were shade dried and were coarsely ground into homogenous powder using a mechanical grinder and stored at room temperature. The extraction of the crude drug was carried out by cold maceration followed by the soxhlet extraction method. Ethanol and Water in the ratio of 90:10 was used for the extract preparation.

\section{Quality assessment of $P$. nigrum fruits}

The quality of $P$. nigrum fruits was assessed by evaluating the quality control parameters mentioned in WHO guidelines. Physico-chemical parameters including moisture content, extractive value, and ash value were performed along with phytochemical analysis $[15,16]$. The crude sample of $P$. nigrum fruits were further analyzed for the determination of toxic substances such as Aflatoxins, pesticide residues, and heavy metals. Aflatoxins were determined by HPLC method as per the standard procedure [17]. Aflatoxins B1, B2, G1, and G2 were analyzed in the powdered sample. Analysis of pesticide residue was carried out by Gas Chromatography-Mass spectroscopy (GC-MS) Instrument. The presence of a total of 17 pesticide contaminants was analyzed in crude powdered fruits. And the presence of heavy metals was analyzed by Atomic Absorption Spectroscopy. Heavy metals, namely lead, cadmium, arsenic, mercury, and chromium were tested in the crude powdered sample.

\section{Instrumentation and chromatographic conditions}

HPLC system (Agilent technologies 1220 Infinity II LC) used for the analysis consisted of a system controller, low-pressure gradient pump, solvent delivery module, online degasser, manual sample injector (injection volume ranging between 5 and $20 \mu \mathrm{L}$ ), and UV-Vis detector. A Reversed-phase C-18 column $(5 \mu \mathrm{m}, 4.6 \mathrm{~mm}, 250 \mathrm{~mm}$, ZORBAX) was used for chromatographic separation. The mobile phase was composed of acidic Water adjusted with Acetic acid, and Acetonitrile in different ratios. Samples were analyzed at the flow rate of $1 \mathrm{~mL} / \mathrm{min}$ and the detection wavelength was set at $342 \mathrm{~nm}$. For each analysis, a $20 \mu \mathrm{L}$ sample was injected into the column.

\section{Preparation of standard and sample solution}

A stock of solution of standard Piperine $(1 \mathrm{mg} / \mathrm{mL})$ was prepared by dissolving accurately weighed $10.00 \mathrm{mg}$ of Piperine in $10.00 \mathrm{ml}$ of HPLC grade methanol with the help of a sonicator. Further working standard solutions 
were prepared by diluting the stock solution with the mobile phase.

For the preparation of the sample, accurately weighed $10 \mathrm{mg}$ of crude powdered sample and extract of $P$. nigrum fruits was transferred to $10.00 \mathrm{~mL}$ volumetric flask individually containing $5.00 \mathrm{~mL}$ of methanol. The methanolic solution was sonicated for $15.00 \mathrm{~min}$ to ensure the complete dissolution of piperine. The volume was made up to $10.00 \mathrm{~mL}$ with methanol and was used for further analyses. The solution was filtered through a $0.25 \mu \mathrm{m}$ membrane filter prior to their injection into the chromatographic column.

\section{Analytical Quality by design assisted based HPLC method development \\ Defining of analytical target profile (ATP) and critical quality attributes (CQA)}

Defining of Analytical Target Profile (ATP) is the first step in the Analytical QbD. ATP serves as the quality specification of the analytical method which should be achieved so as to attain reliable results. Critical Quality Attributes (CQA's) are the quality characteristics related to method performance. CQAs have to be identified from the defined ATP which will be useful in ascertaining the satisfactory performance of the developed method [10, $18]$.

\section{Optimization of method using design of experiments (DoE)}

The optimization of the analytical method was typically performed on parametric variables using Design of Experiments (DoE) to ensure that maximum understanding is gained while minimizing the total number of experiments. A simple $2^{2}$ full factorial design with 2 factors and 2 levels, resulting in 4 experimental runs was employed in order to identify the optimized analytical conditions. The DoE was developed using Design-Expert software version 12.0, (Stat-Ease Inc., Minneapolis, MN, USA).

\section{Establishment of method operable design region (MODR)}

After performing the experimental runs planned as per $2^{2}$ factorial design, the obtained data was studied in terms of regression models and factor-response relationship, to generate the Method Operable Design Region (MODR). From the established MODR the optimized chromatographic conditions were predicted based on the specified target or goals of each CQA in terms of overlay plot. Within the design region, all the specifications mentioned in the ATP are fulfilled at a specified risk level.

\section{Validation of the optimized method}

Validation of the optimized RP-HPLC method was performed as per ICH Q2 (R1) guidelines [19]. The described method was extensively validated in terms of system suitability, linearity, LOD, LOQ, Intra-day precision, Interday precision, and accuracy.

\section{Results \\ Quality assessment of $P$. nigrum fruits}

Quality assessment of herbal drugs is one of the most essential and crucial tasks which enables the determination of quality and safety of the crude drug. Evaluation of physicochemical properties serves as a tool for quality control and identification of crude drugs. Physicochemical parameters such as the moisture content, aqueous soluble extractive value, alcohol soluble extractive value, total ash value, acid insoluble ash value, and water-soluble ash value was found to be $7.6 \pm 0.69,8.67 \pm 0.58$, $9.83 \pm 0.76, \quad 3.83 \pm 0.29, \quad 0.45 \pm 0.21$, and $2.67 \pm 0.29 \%$ $\mathrm{w} / \mathrm{w}$, respectively.

The preliminary phytochemical analysis gives a brief idea about the presence of various secondary metabolites in medicinal plant materials. The preliminary phytochemical analysis of $P$. nigrum fruits revealed the presence of important secondary metabolites such as alkaloids, flavonoids, tannins, and steroids whereas phenols, saponins, and glycosides were found to be absent.

Determination of toxic substances in herbal drugs is one of the major criteria for the assessment of quality in herbal drugs. Determination of Aflatoxins, heavy metals, and pesticide residue is a prerequisite criterion for the export of herbal drugs to foreign countries. Hence, this serves as a vital measure for defining the quality of herbal drugs or products [20]. The HPLC chromatogram obtained from the Aflatoxins analysis in the sample is depicted in Fig. 1. Our earlier study has
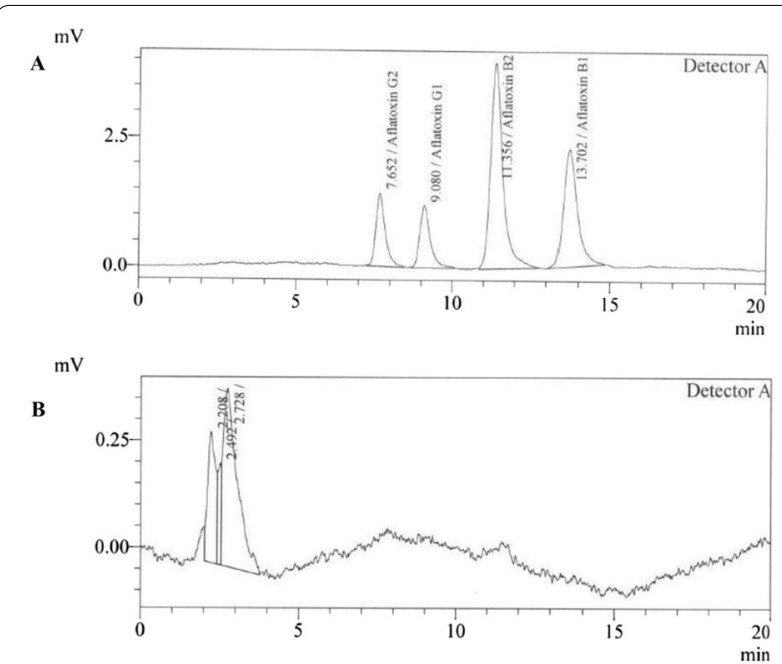

Fig. 1 HPLC chromatograms for (A) standard aflatoxins and (B) $P$. nigrum sample 
reported the retention time for Aflatoxins standards B1, B2, G1, and G2 as 13.70, 11.35, 9.08, and $7.65 \mathrm{~min}$, respectively [11]. From the sample chromatogram, it can be observed that no significant peaks are obtained at the above mentioned retention times, indicating the absence of Aflatoxins in the crude P. nigrum sample. Further, the pesticide residues and heavy metals in the sample were found to be below the limit of quantification. Where, the quantification limit for pesticide residues, lead, cadmium, mercury, arsenic and chromium being $0.01 \mathrm{mg} / \mathrm{kg}, 1.1 \mathrm{mg} / \mathrm{kg}, 0.5 \mathrm{mg} / \mathrm{kg}, 0.1 \mathrm{mg} / \mathrm{kg}$, $0.1 \mathrm{mg} / \mathrm{kg}$, and $0.5 \mathrm{mg} / \mathrm{kg}$, respectively.

\section{Initial method development}

Initial chromatographic conditions were selected based on a thorough literature survey particularly relating to the physicochemical properties of the piperine such as its $\mathrm{pKa}$, solubility, acidic nature, etc. most of the previously published studies have used organic solvents such as methanol, acetonitrile, etc. along with aqueous phase adjusted to high acidic $\mathrm{pH}$ and buffer solutions [21-27]. Further utilization of different column conditions, flow rate, and wavelength has also been observed. Moreover, the previously reported literature exhibits peaks with poor resolution or increased retention time. Taking a gist from the previous studies several preliminary trials were conducted, amongst them a mobile phase consisting of a systemic composition of Acetonitrile, water, and acetic acid as the $\mathrm{pH}$ modifier with suitable flow rate and wavelength was used for the quantitative estimation of piperine.

\section{QbD based RP-HPLC method development}

The predetermined quality characteristics that are known to enhance the method performance are referred to as Analytical target profile. The selection of ATP is purely dependent on the quality attributes that we want in the method. Defining of ATP is the primary step of AQbD concept. TheATP of the proposed analytical method is to achieve a good separation for quantification of Piperine, with lesser tailing factor and peak width along with acceptable analysis time. Based on the above-mentioned ATP, CQAs were identified as Tailing factor (Not more than 2) and Peak width (Not more than 2).

\section{Method optimization by DoE}

As per the adopted per $2^{2}$ full factorial design, two independent variables, i.e., \% concentration of Acetic acid in aqueous phase (X1) and mobile phase ratio (X2) were varied at two different levels that were coded for low and high ( -1 and +1 respectively). Tailing factor (R1) and peak width (R2) were selected as the dependent or response variables. The DoE software was used to gain information on the critical values required to achieve the desired response of the selected independent variables.

The response, tailing factor (R1) and peak width (R2) obtained for each chromatographic trial are summarized in Table 1. Further, statistical optimization of the analytical method was performed by comparison of several statistical parameters, provided by DesignExpert ${ }^{\circledR}$ Software, Version 12. The statistical data of the applied design is summarized in Table 2. The relationship between the selected independent and dependent variables was derived by studying the mathematical

Table 1 Selected factor combinations for Piperine as per $2^{2}$ full factorial design

\begin{tabular}{|c|c|c|c|c|c|c|}
\hline \multirow[t]{2}{*}{ Code } & \multicolumn{2}{|c|}{ Coded levels } & \multicolumn{2}{|c|}{ Actual values } & \multicolumn{2}{|c|}{ Responses } \\
\hline & $\mathrm{X} 1$ & $\mathrm{X} 2$ & $\mathrm{X} 1$ (\%) & $\mathrm{X} 2$ & R1 & $\mathrm{R} 2$ \\
\hline $\mathrm{T} 1$ & -1 & -1 & 0.05 & $60: 40$ & 1.31 & 0.49 \\
\hline $\mathrm{T} 2$ & -1 & +1 & 0.05 & $70: 30$ & 1.23 & 0.43 \\
\hline T3 & +1 & +1 & 1 & $70: 30$ & 1.47 & 0.55 \\
\hline T4 & +1 & -1 & 1 & $60: 40$ & 1.57 & 0.62 \\
\hline
\end{tabular}

$X 1$-conc. of acetic acid (\%); X2- mobile phase ratio, $R 1$-tailing factor, $R 2$ - peak width

Table 2 Summary of statistical parameters and polynomial equation

\begin{tabular}{llll}
\hline Response & $\boldsymbol{P}$ value & Model significance & Polynomial equation \\
\hline Piperine & & & $+1.39+0.1250 * \times 1-0.0450 * \times 2$ \\
R1 & 0.0376 & Significant & $+0.5225+0.0625 * \times 1-0.0325 * \times 2$ \\
R2 & 0.0355 & Significant &
\end{tabular}

$\mathrm{X} 1$ and $\mathrm{X} 2$ are independent variables where, $\mathrm{X} 1$ - conc. of acetic acid in aqueous phase and $\mathrm{X} 2$ - mobile phase ratio 
expression in the form of polynomial equations. A positive sign of coefficient indicates a synergistic effect while a negative term indicates an antagonistic effect upon the response. The larger coefficient means that the independent variable has a more potent influence on the response. Graphical demonstration in the form of Response Surface Plot was generated (Fig. 2) to understand the effect of each factor on responses. The response surface plots provide an overview of the relationship between each dependent variable (CQA's) and independent variables. Response Surface Plot shows the colored regions from blue to red indicating the intensity of the responses from lower to higher end. From the plot, it is observed that by decreasing the level of variable X1, i.e., concentration of acetic acid in the aqueous phase, the value of both the responses R1and R2 decreases which means that by decreasing the concentration of acetic acid in the aqueous phase tailing factor and peak width decreases. This further indicates that variable X1 has a significant impact on response R1 and R2 when compared to variable X2.

\section{Establishment of MODR}

Method operable design region (MODR) is a multidimensional combination and interaction of independent factors which further lead to the selection of acceptable operating ranges that assure quality. Figure 3 shows MODR (overlay plot) with the optimum region as a design space in yellow shade and selected method conditions were represented using flag. From the method operable Design region, analytical trial T1 (Conc. Of Acetic acid $0.05 \%$ and Mobile phase ratio 60:40) and T2 (Conc. Of Acetic acid 0.05\% and Mobile phase ratio 70:30) falls under the region of successful operating ranges and fulfills the criteria of ATP and CQA for HPLC method. Among both, the trials T2 having Conc. Of Acetic acid $0.05 \%$ and Mobile phase ratio $70: 30$ was selected as optimized HPLC method due to its ability to give lesser tailing factor and peak width (Table 3).

\section{Quantitative estimation of Piperine}

The optimized method was further used for the quantification of Piperine in crude $P$. nigrum fruits as well as in the extract. The quantitative estimation revealed the presence of $3.6 \% \mathrm{w} / \mathrm{w}$ and $5.62 \% \mathrm{w} / \mathrm{w}$ of Piperine in crude powder and extract respectively. The HPLC chromatograms for standard Piperine and samples have been depicted Fig. 4.

\section{Method validation}

The developed RP-HPLC method was validated to confirm its suitability for its intended purpose as described in ICH Q2 (R1) guidelines. The validation parameters of the proposed RP-HPLC method are summarized in Table 4 which was found to be within the standard limits specified in ICH Guidelines.

The system suitability of the developed method was confirmed by the percent Relative Standard Deviation (RSD) of different parameters such as peak area, retention time (Rt), and tailing factor. The percent RSD of peak area, retention time, and tailing factor $(<2)$ were within the acceptable limits. The linear calibration curve for piperine was obtained for the selected concentration range (Fig. 5). The LOD and LOQ were determined from the linear regression data obtained from the calibration curve. The reproducibility and repeatability indicate the Precision of an analytical method. The lower intra-day
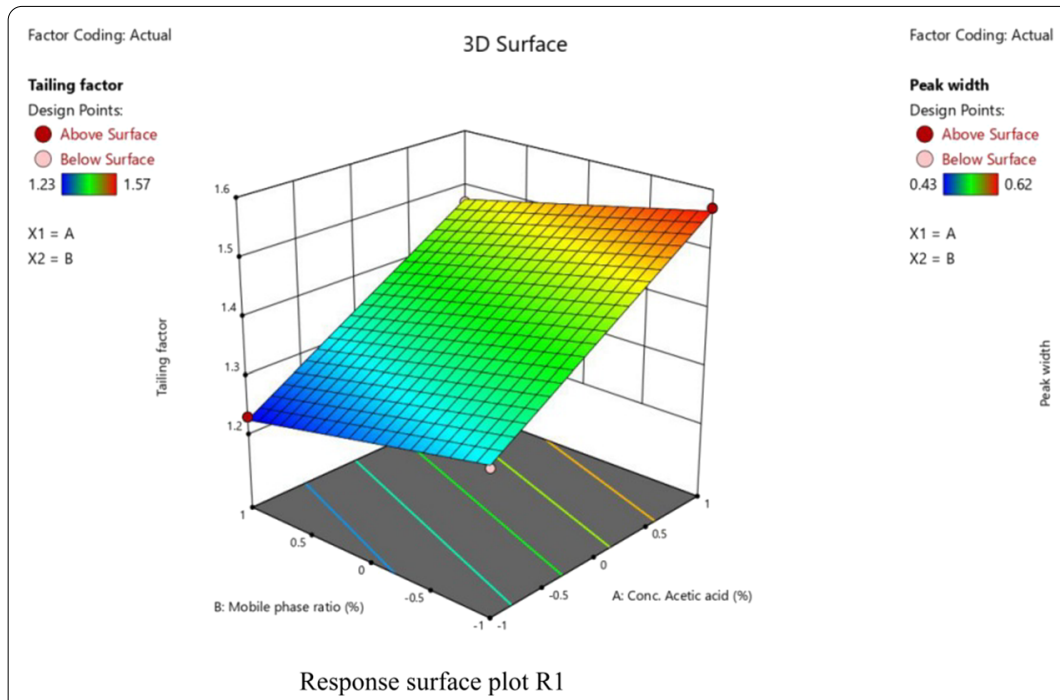

Fig. 2 Response surface plot for optimization of HPLC method for Piperine 


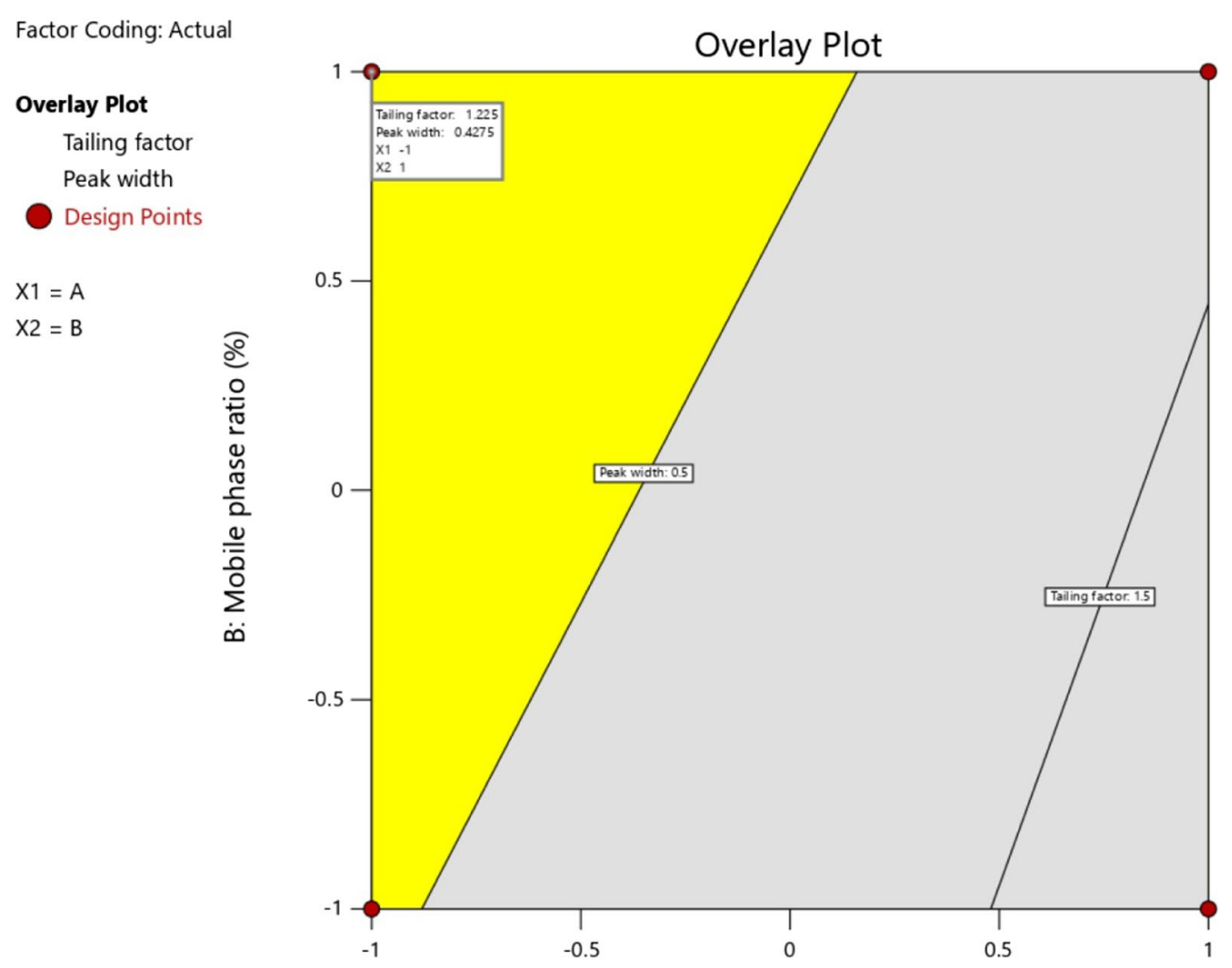

A: Conc. Acetic acid (\%)

Fig. 3 MODR for optimization of HPLC method for Piperine

Table 3 Optimized chromatographic conditions

\begin{tabular}{ll}
\hline Parameters & Chromatographic conditions \\
\hline Stationary Phase & ZORBAX C-18 (250 mm × 4.6 mm, $5 \mu)$ column \\
Mobile phase & Acetonitrile:Water (0.05\% acetic acid) \\
Mobile phase ratio & $70: 30$ \\
Flow rate & $1.00 \mathrm{~mL} / \mathrm{min}$ \\
Detection wavelength & $342.00 \mathrm{~nm}$ \\
Injection volume & $20.00 \mu \mathrm{L}$ \\
Retention time & $5.5 \mathrm{~min}$ \\
\hline
\end{tabular}

and inter-day \% RSD values for piperine demonstrated the high precision of the developed method. The \% recovery of the piperine obtained from the sample indicates a good accuracy of the developed method.

\section{Discussion}

The present research work was carried out to endeavor the development of Analytical Quality by designassisted RP-HPLC method for estimation of Ppiperine in P.nigrum fruits. Though many studies have been conducted on the RP-HPLC method for analysis of Piperine, our study stands out amongst them as it reports the utilization of the Analytical QbD concept. With the help of AQbD principles, a suitable ATP has been developed which serves as a quality specification guide for the development of the analytical method. Based on the ATP, Critical Quality Attributes were identified. By taking into consideration the critical analytical parameters such as concentration of acids used in mobile phase and mobile phase ratios experiments were designed by DoE tools. Here, the CQAs were thoroughly examined by performing statistical analyses such as ANOVA. Polynomial equations and 3-D response surface plots were also developed for identifying the relationship between analytical parameters and CQAs. Further, the optimized chromatographic conditions were predicted from the MODR exhibiting yellow shaded region of successful operating ranges. The optimized chromatographic condition was then applied for quantitative estimation of Piperine in crude and extracted $P$. nigrum fruits which were found to be $3.6 \% \mathrm{w} / \mathrm{w}$ and $5.62 \% \mathrm{w} / \mathrm{w}$, respectively. Apart from the development of AQbD assisted RP-HPLC method our study also reports the data on the Quality 




HPLC Chromatogram for Standard Piperine



HPLC Chromatogram for Piperine in crude P. nigrum fruits

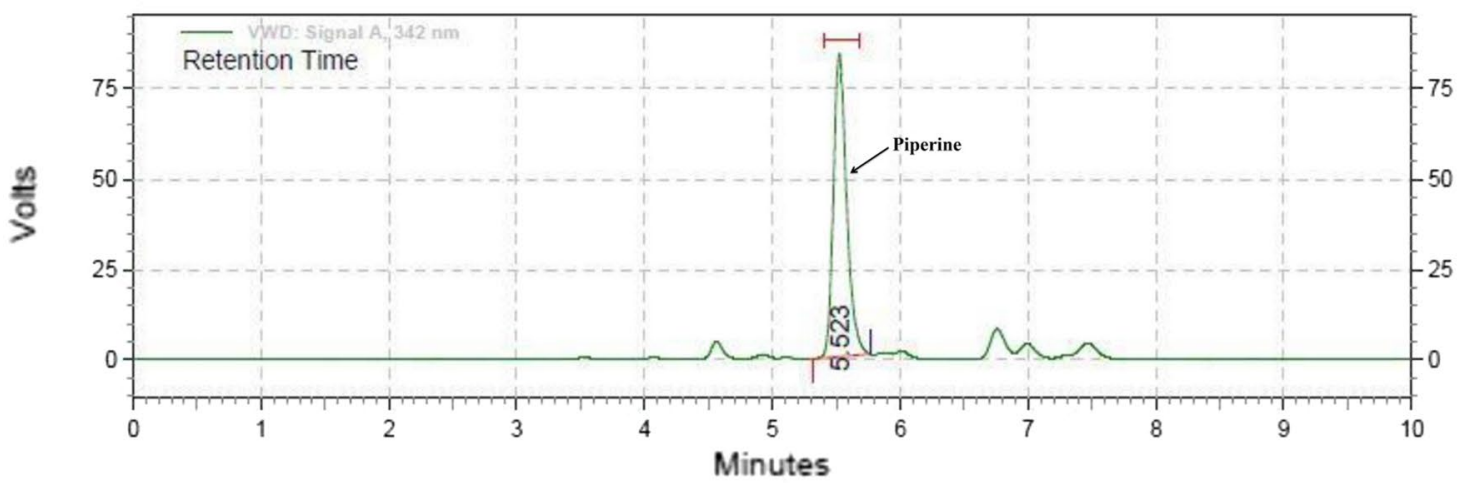

HPLC Chromatogram for Piperine in $P$. nigrum fruit extract

Fig. 4 HPLC chromatograms for standard Piperine, crude P. nigrum L. fruits and extract

assessment of $P$. nigrum fruits with special reference to the estimation of toxic substances found in herbal crude drugs. The study has also represented the Phytochemical and Physico-chemical characteristics of the P. nigrum fruits. Valuable data on the determination of Aflatoxins, pesticide residues, and heavy metals have been reported which is mainly considered a prerequisite by regulatory authorities for ensuring the quality and safety of herbal drugs.

\section{Conclusions}

In the present research work, AnalyticalQbD-assisted RP-HPLC method was developed and validated for the quantitative estimation of Piperine in $P$. nigrum fruits and its extract. ATP and CQAs for the proposed method was outlined with the execution of chromatographic trials as per $2^{2}$ full factorial design. Based on the obtained Design space, optimized chromatographic conditions were predicted. Furthermore, the crude $P$. nigrum was 
Table 4 Summary of validation parameters

\begin{tabular}{|c|c|}
\hline Validation parameters & Piperine \\
\hline \multicolumn{2}{|l|}{ System suitability } \\
\hline \multicolumn{2}{|l|}{ Retention time } \\
\hline Mean $\pm S D$ & $5.54 \pm 0.003$ \\
\hline$\%$ RSD & 0.05 \\
\hline \multicolumn{2}{|l|}{ Peak area } \\
\hline Mean $\pm S D$ & $20,156,202 \pm 120,229$ \\
\hline$\%$ RSD & 0.59 \\
\hline \multicolumn{2}{|l|}{ Tailing factor } \\
\hline Mean \pm SD & $1.24 \pm 0.01$ \\
\hline$\%$ RSD & 0.68 \\
\hline \multicolumn{2}{|l|}{ Linearity } \\
\hline Linearity range $(\mu \mathrm{g} / \mathrm{mL})$ & $5.00-25.00$ \\
\hline Correlation-coefficient & 0.9986 \\
\hline $\mathrm{LOD}(\mu \mathrm{g} / \mathrm{mL})$ & 1.12 \\
\hline LOQ $(\mu \mathrm{g} / \mathrm{mL})$ & 3.41 \\
\hline \multicolumn{2}{|l|}{ Precision } \\
\hline Intra-day (\%RSD) & 1.35 \\
\hline Inter-day (\%RSD) & 1.56 \\
\hline \multicolumn{2}{|l|}{ Accuracy } \\
\hline \multicolumn{2}{|l|}{$80 \%$} \\
\hline$\%$ Recovery & $99.85 \pm 0.28$ \\
\hline \multicolumn{2}{|l|}{$100 \%$} \\
\hline$\%$ Recovery & $101.20 \pm 0.02$ \\
\hline \multicolumn{2}{|l|}{$120 \%$} \\
\hline$\%$ Recovery & $96.35 \pm 0.05$ \\
\hline
\end{tabular}

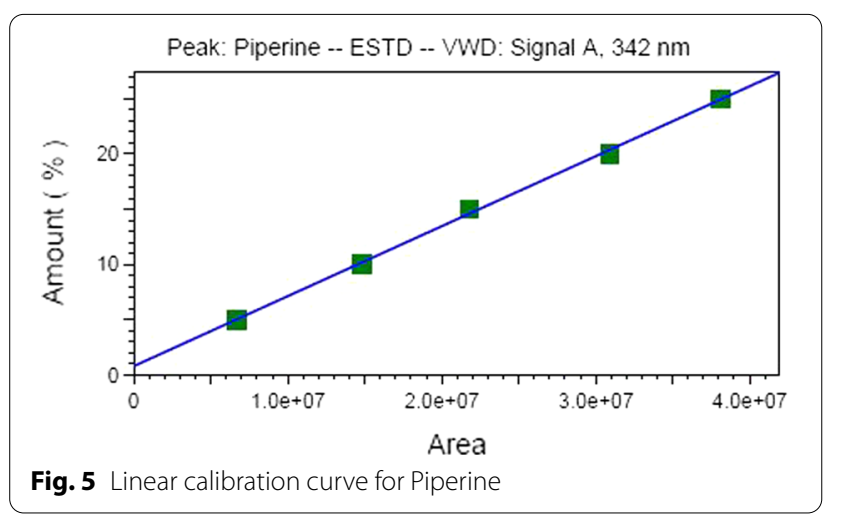

also extensively evaluated for quality control parameters, which was useful for ascertaining the quality of the herbal drug under study. Employment of the QbD tools has helped in developing a chromatographic method that has the potential of providing reproducible and reliable results along with the reduction in analysis time and cost. From the above findings, we can affirm that the application of the QbD approach for the standardization of herbal drugs can serve as an important tool for quality standardization of herbal drugs.

\section{Abbreviations}

QbD: Quality by Design; RP-HPLC: Reverse Phase High Performance Liquid Chromatography; ATP: Analytical Target Profile; CQA: Critical Quality Attributes; DoE: Design of Experiments; MODR: Method Operable Design Region; LOD: Limit of Detection; LOQ: Limit of Quantification.

\section{Acknowledgements}

The authors would like to sincerely thank the Principal, KLE College of Pharmacy, Belagavi for providing necessary facilities. Authors are also thankful to The Himalaya Drug Company, Bengaluru for providing standard Piperine as a gift sample.

\section{Authors' contributions}

VPG carried out the experimental work. VSM and VPG equally contributed in framing and writing of manuscript. KKH revised and edited the final manuscript file. All authors have read and approved the manuscript.

\section{Funding}

Not applicable.

\section{Availability of data and material}

The data used to support the findings of this study are available from the corresponding author upon request.

\section{Declarations}

Ethics approval and consent to participate

Not applicable.

\section{Consent for publication}

Not applicable.

\section{Competing interests}

The authors declare that they have no competing interests.

\section{Author details}

${ }^{1}$ Department of Pharmaceutical Quality Assurance, KLE College of Pharmacy, Belagavi, KLE Academy of Higher Education and Research, Belagavi, Karnataka, India. ${ }^{2}$ Department of Pharmacognosy, Cauvery College of Pharmacy, Mysore, Karnataka, India.

Received: 8 September 2021 Accepted: 26 January 2022

Published online: 05 February 2022

\section{References}

1. ParabGaonkar V, Hullatti K (2020) Indian traditional medicinal plants as a source of potent anti-diabetic agents: a review. J Diabetes Metab Disord 19(2):1895-1908

2. Shi Z, Song D, Li R, Yang H, Qi L, Xin G, Wang D, Song H, Chen J, Hao H, Li P (2014) Identification of effective combinatorial markers for quality standardization of herbal medicine. J Chromatogr A 1345:78-85

3. Gaonkar VP, Hullatti KK, Mannur V (2020) Standardization of Trigonella foenum-graecum L. seeds: a quality by design approach. Indian J Pharm Educ Res 54(4):1072-1079

4. Liang Y, Xie P, Chan K (2004) Quality control of herbal medicine. J Chromatogr B 812:53-70

5. Orlandini S, Pinzauti S, Furlanetto S (2012) Application of quality by design to the development of analytical separation methods. Anal Bioanal Chem 405:443-450

6. ICH (2009) ICH Q8 (R2), Harmonised tripartite guideline, Pharmaceutical development. 
7. Yan B, Li Y, Guo Z, Qu H (2013) Quality by design for herbal drugs: a feedforward control strategy and an approach to define the acceptable ranges of critical quality attributes. Phytochem Anal 25:59-65

8. Zhang L, Yan B, Gong X, Yu L, Qu H (2013) Application of quality by design to the process development of botanical drug products: a case study. AAPS PharmSciTech 14:277-286

9. Parab Gaonkar V, Mannur VS, Mastiholimath VS, Hullatti K (2020) Development and evaluation of herbal supplement: a quality by design approach. Indian J Pharm Sci 82(4):640-649

10. Gurrala S, Shivaraj SCVS, Panikumar DA, Saraf G (2019) Analytical quality by design assisted hplc method for quantification of canagliflozin/metformin and stability studies. Indian J Pharm Educ Res 53:s699-s708

11. Parab Gaonkar V, Hullatti K (2020) Quality assessment and RP-HPLC method development for estimation of curcuminoids in Curcuma Ionga: a quality by design approach. J Liq Chromatogr Relat Technol 44(1-2):95-102

12. Takooree H, Aumeeruddy MZ, Rengasamy KR, Venugopala KN, Jeewon $R$, Zengin G, Mahomoodally M (2019) A systematic review on black pepper (Piper nigrum L.): from folk uses to pharmacological applications. Crit Rev Food Sci Nutr 59:S210-S243

13. Khare CP (2008) Indian medicinal plants an illustrated dictionary. Springer, Berlin

14. Sebastian P (2006) Ayurvedic medicine: the principles of traditional practice. Churchill Livingstone Elsevier, New York

15. World Health Organization (1998) Quality control methods for medicinal plant materials. WHO, Geneva

16. Khandelwal KR, Sethi V (2014) Practical pharmacognosy, 24th edn. Nirali Prakashan Maharashtra, Pune

17. World Health Organization (2007) WHO guidelines for assessing quality of herbal medicines with reference to contaminants and residues. $\mathrm{WHO}$ Geneva

18. Sylvester B, Tefas L, Vlase L, Tomuta I, Porfire A (2018) A quality by design $(\mathrm{QbD})$ approach to the development of a gradient high-performance liquid chromatography for the simultaneous assay of curcuminoids and doxorubicin from long-circulating liposomes. J Pharm Biomed Anal. https://doi.org/10.1016/j.jpba.2018.06.018

19. ICH (1994) ICH Q2 (R1), harmonised tripartite guideline, validation of analytical procedures: text and methodology.

20. Tripathy V, Basak BB, Varghese TS, Saha A (2015) Residues and contaminants in medicinal herb: a review. Phytochem Lett 14:67-78

21. Khismatrao A, Bhairy S, Hirlekar S (2018) Development and validation of RP-HPLC method for simultaneous estimation of curcumin and piperine. Int J App Pharm 10(5):43-48

22. Upadhyay V, Sharma N, Joshi HM, Malik A, Mishra M, Singh BP, Tripathi S (2013) Development and validation of rapid RP-HPLC method for estimation of piperine in Piper nigrum L. Int J Herb Med 1(4):6-9

23. Shah U, Patel S, Raval M (2018) Stability indicating reverse phase HPLC method for estimation of rifampicin and piperine in pharmaceutical dosage form. Curr Drug Discov Technol 15:54-64

24. Rodriguez EL, Zhang C, Woolfork AG, Li Z, Bi C, Kaur H, Juritsch A, Moreau $R$, Hage D (2021) Analysis of curcumin and piperine in biological samples by reversed-phase liquid chromatography with multi-wavelength detection. J Chromatogr B 1162:122487

25. Setyaningsih D, Santoso YA, Hartini YS, Murti YB, Hinrichs W, Patramurti C (2021) A Isocratic high-performance liquid chromatography (HPLC) for simultaneous quantification of curcumin and piperine in a microparticle formulation containing Curcuma longa and Piper nigrum. Heliyon 7:e06541

26. Chaudhari VS, Borkarb RM, Murty US, Banerjee S (2020) Analytical method development and validation of reverse-phase high-performance liquid chromatography (RP-HPLC) method for simultaneous quantifications of quercetin and piperine in dual-drug loaded nano structured lipid carriers. J Pharm Biomed Anal 186:113325

27. Tandel L, Sonone R, Jain V (2020) A novel reverse-phase high-performance liquid chromatographic method for simultaneous estimation of aloe-emodin and piperine in ayurvedic formulation. Asian J Pharm Clin Res 13(2):51-54

\section{Publisher's Note}

Springer Nature remains neutral with regard to jurisdictional claims in published maps and institutional affiliations.

\section{Submit your manuscript to a SpringerOpen ${ }^{\circ}$ journal and benefit from:}

- Convenient online submission

- Rigorous peer review

- Open access: articles freely available online

- High visibility within the field

- Retaining the copyright to your article

Submit your next manuscript at $\boldsymbol{\nabla}$ springeropen.com 